EESTI NSV TEADUSTE AKADEEMIA TOIMETISED 1954. III kd., nr. 4 ИЗВЕСТИЯ АКАДЕМИИ НАУК ЭСТОНСКОИ ССР 1954. Том III, № 4

\title{
К ВОПРОСУ О ПОЗНАНИИ ХИМИЧЕСКОЙ СТРУКТУРЫ КЕРОГЕНА КУКЕРСИТА
}

\author{
А. С. ФОМинА,
}

кандидат технических наук

Количественные зависимости в строении органических соединений на определенном уровне химических знаний получили математическое выражение. Эти закономерности были установлены Кекуле еще в 50-60 годах прошлого столетия.

Вопрос же химического строения органических соединений был разрешен А. М. Бутлеровым в его теории химического строения веществ. В труде «О химическом строении веществ» А. М. Бутлеров пишет: «. .. химическая натура сложной частицы определяется натурой элементарных составных частей, количеством их и химическим строением» ('). Суть этой теории становится еще более ясной из нижеследующей цитаты А. М. Бутлерова: «Понятие о химическом строении, весьма твердо опирающееся на факты, приводит здесь нас а priori к допущению возможности существования веществ, имеющих совершенно одинаковый состав и одинаковую величину частицы и тем не менее совершенно различных между собой в силу различного химического строения» $\left({ }^{2}\right)$.

За последние годы некоторые зарубежные авторы, а также и некоторые наши химики-сланцевики пытаются свести познание химической структуры ископаемых углей и керогенов горючих сланцев к изучению количественных зависимостей связей углерода в массе вещества и на основе такого одностороннего математического анализа связей, при совершенном игнорировании качества связей, делают выводы о химической структуре столь сложных веществ, как кероген горючих сланцев и органическое вещество других твердых горючих ископаемых. В связи с этим и возникает необходимость снова повторять те истины, которые А. М. Бутлеровым были высказаны $80-100$ лет назад.

Еще с прошлого столетия для классификации углей применяли графостатистические методы, основанные на данных элементарного анализа горючих ископаемых. Эти методы принесли определенную пользу при классификации горючих ископаемых, в установлении относительной степени метаморфизма органического материала, в выявлении определенных технологических свойств горючих ископаемых и т. д. Однако эти методы не решали вопросов химической структуры органических веществ твердых горючих ископаемых.

Некоторые зарубежные авторы, в частности Д. В. ван Кревелен $\left({ }^{7}\right)$, придают большое значение статистическим методам в познании химиче- 
ской структуры твердых горючих ископаемых. В ряде последних работ, в частности в одной из опубликованных в 1954 году $\left({ }^{16}\right)$, Д. В. ван Кревелен отвергает химические методы исследования химической структуры углей, как методы, связанные с деструкцией сложной молекулы, где не всегда имеется уверенность в том, что полученный осколок отражает именно то строение, которое имеет место в исходном веществе. В приведенном труде он определяет химическую структуру на основе данных элементарного анализа и плотности вещества.

Математическое выражение количественных взаимозависимостей между углеродом и водородом Д. В. ван Кревелен строит на количественных зависимостях, выведенных Кекуле. Отсюда он и приходит к заключению, что в алканах количество водорода (через углерод) может быть выражено следующим образом:

$$
\mathrm{H}=2 \mathrm{C}+2 \text {, }
$$

где $\mathrm{H}$ - количество атомов водорода в молекуле и

C - количество атомов углерода.

Для соединений, содержащих в структуре циклы (обозначены через $R)$, вышеуказанная взаимозависимость выражается автором в следующем виде:

$$
\mathrm{H}=2 \mathrm{C}+2-2 R \text {. }
$$

Здесь на замыкание кольца затрачиваются две связи.

Для непредельных углеводородов с двойной и тройной связью уравнение (2) преобразовывается в следующее:

$$
\mathrm{H}=2 \mathrm{C}-2(R-1)-2 \digamma-4 \risingdotseq,
$$

где $R$ - число колец, $=$ и $\equiv$ - число двойных и тройных связей в молекуле.

Для полимеров, где $R>1$, вышеуказанные зависимости выражаются следующим приближенным уравнением:

$$
\mathrm{H} \approx 2 \mathrm{C}-2 R-2 \digamma-4 \mid \equiv .
$$

Далее, автор делает допущение, что в углеводороде число тройных связей незначительно, а все двойные связи являются ароматическими. На основании этого уравнение (4) преобразовывается им следующим образом:

$$
2 \mathrm{~F}_{a} \approx 2 \mathrm{C}-\mathrm{H}-2 \mathrm{R},
$$

где $\digamma_{a}-$ число ароматических двойных связей.

Автор признает, что во многих случаях невозможно абсолютное определение количества водородных и углеродных атомов в полимере, и поэтому приближенное уравнение (5) преобразовывает в следующее:

где $2 F_{a} / \mathrm{C}$ - ароматическая часть углерода,

$$
2 \mid={ }_{a} / \mathrm{C} \approx(1-\mathrm{H} / \mathrm{C})+(1-2 R / \mathrm{C}),
$$

$\mathrm{H} / \mathrm{C}$ - отношение количества водорода к углероду,

$2 R / C$ - индекс кольчатости в системе.

На основании последнего Д. В. ван Кревелен устанавливает зависимость между элементарным составом и структурой углеводорода. Таким же порядком устанавливается зависимость между элементарным составом и структурой любого гетероатомного органического соединения. Для этого вводятся поправки на гетероатомы, замещающие водород, и соеди- 
нение как бы приравнивается к углеводороду. Само собой понятно, что требуется знание функций гетероатомов и количества функциональных групп, а следовательно, и молекулярного веса. Правда, в тех случаях, когда все-таки молекулярный вес определить невозможно, автор ведет весь расчет на грамм-атом углерода. Поправки производятся только на те функциональные группы, в которых гетероатом замещает водородную связь, поэтому такие функциональные группы, как гидроксил, мостиковый кислород или гетероатомный кислород, не учитываются: Корректирование отношения водорода к углероду в гетероатомном соединении, содержащем кислород и азот, Д. В. ван Кревелен осуществляет согласно следующей формуле:

$$
\begin{aligned}
\left(\frac{\mathrm{H}}{\mathrm{C}}\right)_{\text {скорр. }}=\left(\frac{\mathrm{H}}{\mathrm{C}}\right)_{\text {экспер. }}+\frac{\mathrm{O}_{\text {карбонил }}}{\mathrm{C}}+\frac{\mathrm{O}_{\text {хинон }}}{\mathrm{C}}+\frac{\mathrm{O}_{\text {карбоксил }}}{\mathrm{C}}- \\
-\frac{\mathrm{N}_{\mathrm{NH}_{2}}}{\mathrm{C}}-\frac{\mathrm{N}_{\mathrm{NH}}}{\mathrm{C}} .
\end{aligned}
$$

Затем автор определяет количество ароматического углерода в соединении из следующего уравнения:

$$
2{ }_{a} / \mathrm{C} \approx\left(1-\mathrm{H} / \mathrm{C}_{\text {скорр. }}\right)+(1-2 R / \mathrm{C}) .
$$

При этом индекс кольчатости выводится через атомные объемы. В качестве примера, подтверждающего правильность вышеуказанных выкладок, автор приводит сложную структурную единицу гетероатомного полимера с основной ароматической структурой. При этом он дает количество атомов углерода, водорода, функциональных групп, ароматических колец; отсюда следует, что ему известен и молекулярный вес этой структурной единицы. На основании этих данных он производит корректировку отношения водорода к углероду и затем определяет отношение количества ароматических атомов углерода ко всему количеству углерода в структурной единице $2 \digamma_{a} / \mathrm{C}$. В самом деле, вычисленное количество ароматического углерода соответствует действительному в приведенном структурном элементе, но это ничего еще не говорит о возможности определения структуры (порядка связи) неизвестного соединения, так как этим показателям могут соответствовать и другие конфигурации структурной единицы. Если же не имеется возможности точно установить молекулярный вес и функциональные группы, то подобный расчет окажется вообще беспредметным. Ничем нельзя ни доказать, ни опровергнуть вымышленную структуру исследуемого вещества, так как в целом молекула или ее структурная единица не могут быть охарактеризованы известными химическими и физическими методами.

И. Шувер и Д. В. ван Кревелен $\left({ }^{17}\right)$ устанавливают структуру угля, вернее долю ароматического углерода в веществе угля, на основе молекулярной рефракции. Судя по данным В. М. Татевского $\left({ }^{11}\right)$, и в этом случае исходные положения авторов не вскрывают тех качественных особенностей химических связей элементов и их групп, которые теоретически и экспериментально уже доказаны в области химического строения углеводородов и, следовательно, должны учитываться при изучении химической структуры производных углеводородов. Не вдаваясь в возможности и перспективы изучения химической структуры горючих ископаемых другими методами, развиваемыми Д. В. ван Кревеленом, можно сказать, что на основе одних количественных зависимостей между углеродом и водородом этого вопроса не разрешить.

С. С. Семенов при установлении химической структуры углеводородов и горючих ископаемых также исходит из количественных зависимостей 
углеродных связей. (Доклады на научной сессии Отделения технических и физико-математических наук АН ЭССР в марте 1954 года и научной конференции Таллинского политехнического института в апреле того же года.) Поскольку эти методы не охватывают качества химических связей даже непосредственно связанных элементов, не говоря уже о влиянии непосредственно не связанных элементов, то казалось бы не следовало и уделять им внимания. Но на самом деле этого сделать нельзя, так как на основе этих чисто количественных взаимозависимостей делаются далеко идущие выводы о структуре керогенов горючих сланцев, отвергаются химические пути изучения и методы математического выражения количества связей характеризуются как «высокотеоретические методы». При поверхностном знакомстве и некритическом отношении этот путь является весьма соблазнительным по своей легкости и якобы «быстроте» достижения конечных результатов. Поскольку С. С. Семенов на основе выведенных им уравнений решает вопросы химической структуры в первую очередь керогена кукерских сланцев, изучением химической природы которых занимаются и другие исследователи, является целесообразным привести подробный разбор всех его исходных положений и выводов в отношении этого горючего ископаемого.

С. С. Семенов определяет число углеродных свя̈зей в парафиновых углеводородах при помощи следующего уравнения:

$$
X_{0}=\frac{\mathrm{C} \cdot M}{12 \cdot 100}-1,
$$

где $X_{0}-$ число углеродных связей в алканах,

С - \% углерода в соединении,

M - молекулярный вес соединения.

Далее, для всякого другого, неалканового углеводорода, где число углеродных связей больше, количество их опеределяется из следующего уравнения:

$$
X_{p \phi}=\frac{\left(\frac{\mathrm{C}}{3}-\mathrm{H}\right) M}{2 \cdot 100},
$$

где $X_{p \phi}$ - число углеродных связей (расчетное, фактическое),

С-\% углерода,

Н - \% водорода,

M - молекулярный вес.

Разность между (2) и (1), $X_{p \phi}-X_{0}$, по данным автора, дает представление о ненасыщенности соединения или наличии цикличности.

Переходя от углеводородов к гетероатомным соединениям, С. С. Семенов, подобно Д. В. ван Кревелену, производит корректировку на гетероатомы и преобразовывает уравнение (2) в следующее:

$$
X_{p \phi}=\frac{\left\{\frac{\mathrm{C}}{3}-\left[\mathrm{H}+\frac{n_{1}\left(\mathrm{O}_{0}-\mathrm{O}_{\phi}\right)}{16}+\frac{n_{2}\left(\mathrm{~N}_{0}-\mathrm{N}_{\phi}\right)}{14}+\frac{n_{3}\left(\mathrm{~S}_{0}-\mathrm{S}_{\phi \phi}\right)}{32}+\ldots\right]\right\} M}{2 \cdot 100},
$$

где $n_{1}, n_{2}, n_{3} \ldots$ - показатели валентности элементов,

$\mathrm{O}_{\phi}, \mathrm{N}_{\phi}, \mathrm{S}_{\phi}$ - гетероатомы, не связанные с углеродом всеми валентностями.

Как видно из приведенных уравнений $(1),(2)$ и (3), они не могут дать больше того, что в свое время было дано Кекуле, т. е. только количество связей. Но, как известно, около 100 лет назад А. М. Бутлеров показал, 
что для установления химического строения вещества этого недостаточно. Это только одна сторона вопроса. В. М. Татевский ('1) в своей монографии пишет: «Молекула - единая химическая частица - не представляет собой простого механического сочетания отдельных химических связей, атомов и атомных групп. Даже если бы отдельные связи при переходе от одной молекулы к другой практически полностью сохраняли особенности их строения и характерные для них свойства, само по себе увеличение числа этих связей и изменение способа их сочетания (порядка химической связи атомов) привело бы к новым, особым свойствам всей молекулы в целом. Поэтому было бы неправильно пытаться полностью сводить все особенности химического строения молекулы, все особенности ее поведения к особенностям ее отдельных связей». Однако С. С. Семенов считает эти уравнения универсальными и, пользуясь ими, устанавливает структуру твердых горючих ископаемых, в частности керогена кукерсита. Он делает предположение (как и Д. В. ван Кревелен по отношению к углям), что в керогене не содержится других двойных связей, кроме ароматических, и, пользуясь данными элементарного анализа керогена кукерсита, производит расчет ненасыщенности или цикличности вещества керогена. Поскольку при этом делается еще ряд произвольных допущений, представляется целесообразным привести здесь весь ход расчетов и выводов автора.

Элементарный состав образца керогена кукерсита, исследованного С. С. Семеновым:

$\mathrm{C}-77,61 ; \mathrm{H}-9,15 ; \mathrm{S}-1,39 ; \mathrm{O}-11,37 ; \mathrm{N}-0,18$ и $\mathrm{Cl}-0,30$ (в процентах, при непосредственном определении всех элементов).

Расчет:

$$
X_{p \phi}=\frac{\left\{\frac{77,61}{3}-\left[9,15+\frac{11,37}{8}+\frac{1,39}{16}+\frac{3 \cdot 0,18}{14}+\frac{0,3}{35,5}\right]\right\} 1000}{2 \cdot 100}=75,8
$$

В расчете произвольно допускается, что 1) двойные связи только ароматические, 2) молекулярный вес условно принимается равным 1000 , т. е. не соответствует ни молекуле, ни структурной единице этой молекулы, 3) игнорируется действительная функциональность гетероатомов и количество функциональных групп, 4) совершенно не учитывается качество функциональных групп в зависимости от структуры молекулы.

Далее, автор производит расчет количества углеродных связей, которое должно было бы соответствовать рассчитанному по нижеследующей формуле, если бы углерод керогена находился в алкановом углеводороде:

$$
X_{0}=\frac{77,61 \cdot 1000}{12 \cdot 100}-1=63,7
$$

Затем он находит излишнее количество углеродных связей, т. е. характеризует ненасыщенность или цикличность вещества керогена:

$$
X_{p \phi}-X_{0}=75,8-63,7=12,1 .
$$

Предположим, - говорит Семенов, что органическое вещество керогена имеет нафтеновые неконденсированные циклы с 6 углеродными атомами в цикле. При разности $X_{p \phi}-X_{0}=12,1$ (на условный молекулярный вес 1000) это дало бы углерода $12 \times 6 \times 12,1=871,2$ г, или $87,12 \%$, а фактически в керогене, по элементарному анализу, содержание углерода равно $77,61 \%$. Поэтому автор исключает это предположение как несоответствующее действительности. Он делает второе предположение о том, что в веществе керогена содержатся конденсированные шестичленные 
нафтеновые циклы; в этом случае, по расчету Семенова, на условный молекулярный вес 1000 должно было бы содержаться 15 циклов, или 747 г углерода. Однако и этот вариант автор исключает, ссылаясь на состав продуктов термической деструкции керогена (полукоксования). Наиболее вероятным С. С. Семенов считает предположение, что в керогене кукерсита содержатся ароматические структуры. В этом случае, по расчету автора, достаточно наличия только трех ароматических циклов на условный молекулярный вес 1000. Тогда получается 216 г ароматического углерода и остальной углерод в виде алкановых боковых цепей. Он допускает также сочетание ароматических и нафтеновых циклов, в этом случае ароматических циклов может быть меньше. Хотя последнее допущение имело место в его докладах и тексте отчета (С. С. Семенов и другие, «Изучение природы керогена и разработка предложений по его использованию, Отчет ВНИИПС за 1953 год, Ленинград), тем не менее в выводах отчета (п. 2) автор пишет: «На основании расчета числа углеродных связей в органическом веществе сланца по теоретическим уравнениям, выведенным C. С. Семеновым, доказано наличие циклических, ароматических структур в составе керогена. По предварительным данным можно полагать, что количество углерода, находящегося в ароматических циклах керогена, достигает $20-25 \%$ от общего углерода в органическом веществе».

Правильность своих выкладок, сделанных на основании выведенных уравнений, С. С. Семенов доказывает и вторым расчетным путем. Он говорит: «Представим себе, что все гетероатомы, в соответствии с их валентностями, заменены на водород» и, исходя из элементарного состава керогена кукерсита, производит следующий расчет:

\begin{tabular}{|c|c|c|c|}
\hline кислород & заменяет & $\frac{11,37}{8}=1,42 \Gamma$ & водорода, \\
\hline cepa & ", & $\frac{1,39}{16}=0,08 \Gamma$ & ", \\
\hline азот & ", & $\frac{3.0,18}{14}=0,04 \Gamma$ & ", \\
\hline хлор & , & $\frac{0,3}{35,5}=0,01 \Gamma$ & \\
\hline
\end{tabular}

или гетероатомы заменяют 1,55 г водорода. Из данных элементарного анализа керогена следует, что на 100 граммов вещества имеется 9,15 г водорода. Следовательно, после пересчета гетероатомов на водород, всего водорода будет 10,7 г. Далее автор принимает углерод и полученный водород $(77,61+10,70=88,31)$ за 100 и рассчитывает процентное содержание углерода и водорода в гипотетическом углеводороде. При этом получается $88,05 \%$ углерода и $11,95 \%$ водорода. На основании этих величин С. С. Семенов определяет отношение водорода к углероду в «керогене-углеводороде» и находит, что на один атом углерода приходится 1,63 атома водорода. И вот это отношение оказывается и подтверждает наличие ароматических циклов в гипотетическом «керогене-углеводороде». C. С. Семенов вполне обоснованно указывает, что это вещество не является алкановым, так как в последних отношение водорода к углероду больше 2. Но далее автор высказывает положения, не соответствующие действительности, а именно, что отношение водорода к углероду в нафтенах и олефинах равно 2 и поэтому полученное отношение 1,63 указывает будто бы на наличие ароматических циклов в веществе, Однако это не следует даже из ряда, приведенного Д. В. ван Кревеленом $\left({ }^{7}\right)$, что видно также из отношений приведенного ниже ряда соединений: 
1. Гексан, $\mathrm{H} / \mathrm{C}=2,33$

2. Гексен, $\mathrm{H} / \mathrm{C}=2,00$

3. Циклогексан, $\mathrm{H} / \mathrm{C}=2,00$

4. Циклогексен, $\mathrm{H} / \mathrm{C}=1,67$

5. Декалин, $\mathrm{H} / \mathrm{C}=1,80$

6. Холестан $\mathrm{C}_{27} \mathrm{H}_{48}$ (в боковых цепях $\mathrm{C}_{8} \mathrm{H}_{17}$ и 2 метила), $\mathrm{H} / \mathrm{C}=1,78$

7. Холестадиен $\mathrm{C}_{27} \mathrm{H}_{44}$ (по одной двойной связи в кольцах В и С), $\mathrm{H} / \mathrm{C}=1,63$

8. Холатриен $\mathrm{C}_{24} \mathrm{H}_{36}$ (по одной двойной связи в кольцах $\mathrm{A}, \mathrm{B}$ и $\mathrm{C}$; в боковых цепях изобутильная и две метильные группы), $\mathrm{H} / \mathrm{C}=$ $=1,50$

9. Фукостерин $\mathrm{C}_{29} \mathrm{H}_{47} \mathrm{OH}$ (стерин морских бурых водорослей с двумя двойными связями) $\left({ }^{13}\right), \mathrm{H} / \mathrm{C}=1,66$

10. Холинастерин $\mathrm{C}_{28} \mathrm{H}_{47} \mathrm{OH}$ (стерин морских беспозвоночных с двумя двойными связями), $\mathrm{H} / \mathrm{C}=1,71$

11. Литохолевая кислота $\mathrm{C}_{23} \mathrm{H}_{38}(\mathrm{OH}) \mathrm{COOH}$ (насыщенная оксикислота), $\mathrm{H} / \mathrm{C}=1,75$

12. Апохолевая кислота $\mathrm{C}_{23} \mathrm{H}_{35} \quad(\mathrm{OH})_{2} \mathrm{COOH}$ (с одной двойной связью), $\mathrm{H} / \mathrm{C}=1,67$.

Из небольшого ряда приведенных мономерных веществ следует, что отношение водорода к углероду ниже 2 еще не обусловливает наличия ароматического цикла. Поэтому приведенное С. С. Семеновым доказательство (если даже считать полученное им отношение соответствующим действительному отношению в керогене) нельзя считать состоятельным. Если познание структуры керогена строить на предположениях, то можно привести следующее сопоставление, которое может иметь также отношение к керогену кукерсита. Элементарный состав литобилановой кислоты (производное стеринов) и отношение в ней водорода к углероду (нескорректированное) совпадают с теми же показателями одной из фракций гетероатомных кислот, получающихся при окислительной деструкции керогена кукерсита щелочным перманганатом калия. Это видно из нижеприведенных сопоставлений:

\begin{tabular}{|c|c|c|c|c|}
\hline \multirow{2}{*}{ Наименование } & \multicolumn{3}{|c|}{$\begin{array}{l}\text { Элементарный } \\
\text { состав в \% }\end{array}$} & \multirow{2}{*}{$\begin{array}{c}\text { Отношение H/C } \\
\text { нескорректиро- } \\
\text { ванное }\end{array}$} \\
\hline & C & $\mathrm{H}$ & 0 & \\
\hline $\begin{array}{l}\text { Литобилановая кислота } \\
\text { Гетероатомные кислоты }\left({ }^{14}\right)\end{array}$ & $\begin{array}{l}68,3 \\
67,7\end{array}$ & $\begin{array}{l}9,0 \\
8,98\end{array}$ & $\begin{array}{l}22,7 \\
23,32 *\end{array}$ & $\begin{array}{l}1,58 \\
1,58\end{array}$ \\
\hline
\end{tabular}

* Сумма гетероатомов $(\mathrm{O}+\mathrm{N}+\mathrm{S})$.

Эмпирическая формула литобилановой кислоты $-\mathrm{C}_{24} \mathrm{H}_{38} \mathrm{O}_{6}$, молекулярный вес -422 , структурная формула следующая:

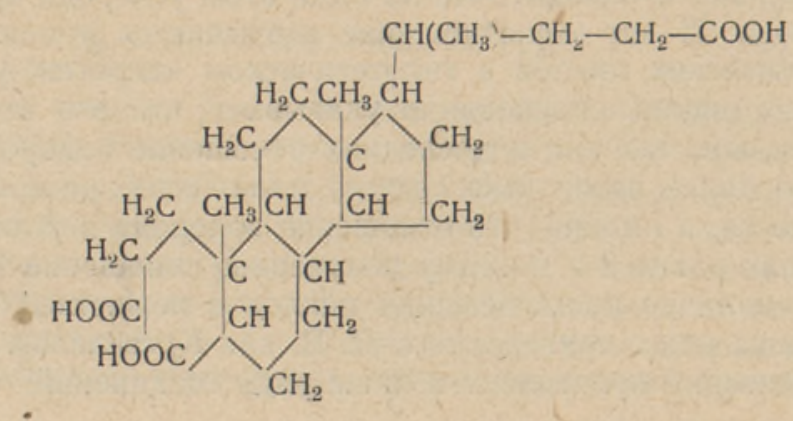


Произведем расчет ненасыщенности или цикличности данной кислоты по С. С. Семенову, с учетом всех данных, т. е. молекулярного веса и функциональных групп:

$$
X_{p \phi}=\frac{\left(\frac{68,3}{3}-\left[9,0+\frac{22,7-11,35}{8}\right]\right)^{422}}{2.100}=26,12
$$

и

$$
X_{0}=\frac{68,3 \cdot 422}{12 \cdot 100}-1=23,0
$$

отсюда $X_{p \phi}-X_{0} \approx 3,0$.

Если установить эту разность на условный молекулярный вес 1000 , то показатель ненасыщенности будет:

$$
\frac{3 \cdot 1000}{422}=7,1
$$

Представим себе, что мы ничего не знаем о структуре этого вещества, так же как и о керогене, и будем строить предположения относительно того, что это может быть за соединение с разностью $X_{p \phi}-X_{0}=7,1$. В этом случае одним из предположений о возможной химической структуре на условный молекулярный вес 1000 может быть предположение о наличии в веществе $1,5-2$ ароматических циклов, в сочетании с алкильными боковыми цепями. При отсутствии возможности проверить это химическими или физическими методами, под такое предположение можно подвести базу за счет новых предположений и, таким образом, прийти к ложным выводам. В то же время видно, что вещество литобилановой кислоты не содержит ни одного ароматического кольца, не имеет ни одной двойной связи и содержит около $46 \%$ углерода в открытых алкановых цепях.

Далее, С. С. Семенов получил для «керогена-углеводорода» $88,05 \%$ углерода и $11,95 \%$ водорода и утверждает, что это должно соответствовать наличию в веществе керогена ароматических циклов. Для того чтобы убедиться в необязательности подобного утверждения, рассмотрим следующее соединение: $\triangle^{3,8}$ холестадиен, эмпирическая формула его $\mathrm{C}_{27} \mathrm{H}_{44}$, молекулярный вес -368 и структурная формула

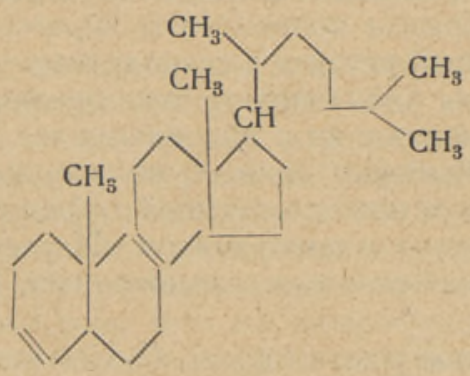

Из структурной формулы видно, что в молекуле имеются две двойные связи и что на условный молекулярный вес 1000 приходится двойных связей $\frac{2 \cdot 1000}{368}=5,5$. При этом в соединении не содержится ни одного ароматического кольца и в то же время элементарный состав его показывает $88,04 \%$ углерода и $11,96 \%$ водорода (показатели, совпадающие с показателями «керогена-углеводорода» С. С. Семенова) и поэтому есте- 
ственно, что порядок ненасыщенности получается такой же, как и для керогена:

$$
\begin{gathered}
X_{p \phi}=\frac{\left[\frac{88,04}{3}-11,96\right] \cdot 1000}{2 \cdot 100}=86,9 \\
X_{0}=\frac{\frac{88,04 \cdot 1000}{12 \cdot 100}-1=72,3}{X_{p \phi}-X_{0}=14,6} .
\end{gathered}
$$

Следовательно, нет никаких теоретических оснований для вывода, который записан в вышеуказанном отчете С. С. Семенова (п. 5) : «Выведенные уравнения для расчета числа углеродных связей в молекуле органического вещества открывают широкие возможности для глубокого изучения строения, создания научной классификации и установления технических свойств различных органических соединений и особенно горючих ископаемых».

С. С. Семенов, сделав выводы о химической структуре керогена на основании расчета углеродных связей, якобы подтверждает их фактическими данными. Однако пояснеения к этим фактическим данным также базируются на односторонних представлениях и поэтому не являются безапелляционными. Рассмотрим и эту часть доказательств. Рядом авторов, в том числе и исследовательской группой С. С. Семенова, проводятся работы по определению функциональных групп в керогене кукерсита (пока кислородсодержащих). К настоящему времени установлено наличие в керогене гидроксильной (нешзвестно, спиртовой или фенольной) сложноэфирной, карбоксильнбй, карбонильной групп, предполагается простая эфирная группа и т. д.

С целью доказательства существования в керогене ароматических циклов и отнесения определяемых гидроксилов к фенольным, а не спиртовым, С. С. Семенов проводит следующие эксперименты с керогеном кукерсита (при исследовании использован концентрат керогена с содержанием органического вещества более 90\%). Концентрат керогена подвергается ряду обработок - спиртовой щелочью, уксусным ангидридом, последовательно спиртовой щелочью и затем соляной кислотой и, наконец, спиртовой щелочью, соляной кислотой и уксусным ангидридом. Препарированные таким образом концентраты керогена подвергаются полукоксованию в алюминиевой реторте в стандартных условнях, т. е. при температуре до $500^{\circ}$. Авторы анализируют газообразные и жидкие продукты полукоксования и сравнивают их с подобными же продуктами исходного концентрата керогена. Выборку данных, полученных С. С. Семеновым и сотрудниками, приводим в нижеследующей таблице (данные из таблиц 8 и 10 отчета С. С. Семенова и сотрудников «Изучение природы керогена и разработка предложений по его использованию», ВНИИПС, Ленинград, 1953).

Приведенные в таблице результаты С. С. Семенов объясняет наличием в керогене бензольных колец со свободными и связанными фенольными гидроксилами. При термическом разложении керогена бензольные кольца со свободными фенольными гидроксилами не изменяясь, а как бы только освобождаясь от связывающих их боковых цепей, переходят в смолу в виде фенолов. После обработкй керогена щелочью (с которой не реагирует спиртовая группа) получаются уже феноляты, при термической обработке которых фенолы не получаются, а происходит разложение фенолятов до кокса и газообразных продуктов; поэтому в смоле образца № 2 


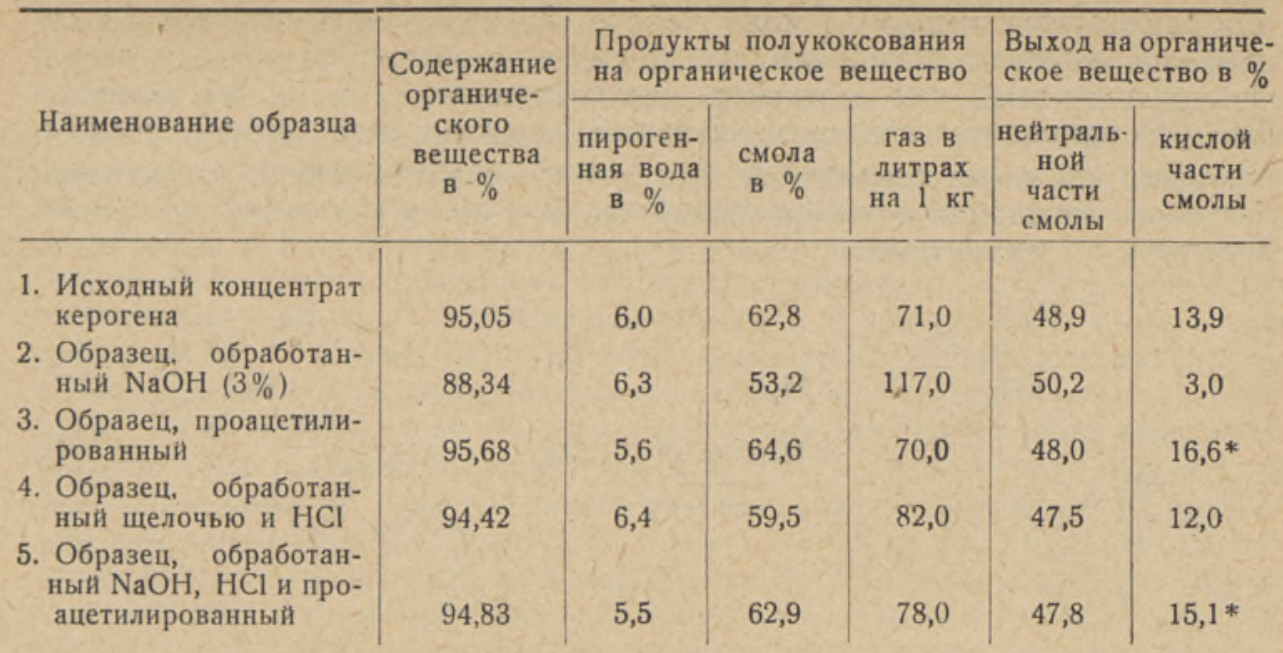

* В том числе и кислоты подсмольной воды для третьего образца $4 \%$ и пятого $-1,8 \%$ (в расчете на уксусную кислоту).

кислая часть составляет всего $3 \%$, вместо $13,9 \%$ смолы исходного, необработанного щелочью керогена. Обработка уксусным ангидридом приводит к ацетилированию фенольных гидроксилов, которые при термическом разложении также переходят в фенолы; то же самое как бы подтверждает обработка образцов 4 и 5. На первый взгляд все кажется логичным, и высказанные предположения как бы подтверждаются экспериментальными данными. Однако при проведении экспериментов и обсуждении полученных данных С. С. Семенов исходит из поведения функциональных групп в мономерных соединениях низкомолекулярной химии и даже в соединениях относительно несложной структуры. Можно ли с такой меркой подходить к сложному высокомолекулярному веществу, как кероген кукерсита? Очевидно, нет.

Химия высокомолекулярных органических соединений за последние два десятилетия накопила столько теоретического и экспериментального материала, что пренебрегать им нет основания. Например, уже твердо установлены факты поведения высокополимерных эфиров по отношению к спиртам и кислотам.

В. В. Коршак $\left({ }^{6}\right)$ пишет, что под действием кислот и спиртов полимерные эфиры подвергаются деструкции. Эти реакции ускоряются как температурой, так и наличием кислых или щелочных катализаторов. Обработка полимерных эфнроз спиртом в присутствии щелочи приводит к алкоголизу, где реагирующим веществом является спирт, а щелочь катализатором, в то время как при мономерных эфирах спиртовая щелочь приводит к омылению, где реагирующим веществом является щелочь, а спирт - растворителем. Кроме того, из литературных данных известно $\left({ }^{13}\right)$, что ряд соединений, относящихся к кислородным производным стеринов, неустойчив по отношению к щелочам; эти соединения подвергаются при подобной обработке перестройке и теряют свойства физиологической активности $\left({ }^{18}\right)$. Обработка некоторых эфиров этого ряда, как, например, 3-ацетат-17-бензоат- $\triangle^{5}$-андростендиола, спиртовой щелочью (1 моль щелочи в метанольном растворе) не затрагивает бензоата совершенно, а ацетильный заместитель подвергается переэтерификации, с образованием в продуктах реакции метилацетата $\left({ }^{13}\right)$. Предполагается, что щелочь в этом случае также играет роль катализатора, так как в результате реак- 
ции расходуется только 0,1 моля щелочи. То же самое отмечается и в отношении уксусного ангидрида: его действие не обязательно только этерифицирующее или, как называют, ацетилирующее. В той же монографии $\left({ }^{13}\right)$ приводится экспериментальный материал ряда авторов, показывающий, что такие соединения, как $\triangle^{1,4}$-холестадиен-3-он в присутствии уксусного ангидрида и следов серной кислоты почти количественно изомеризуются в стерофенол:

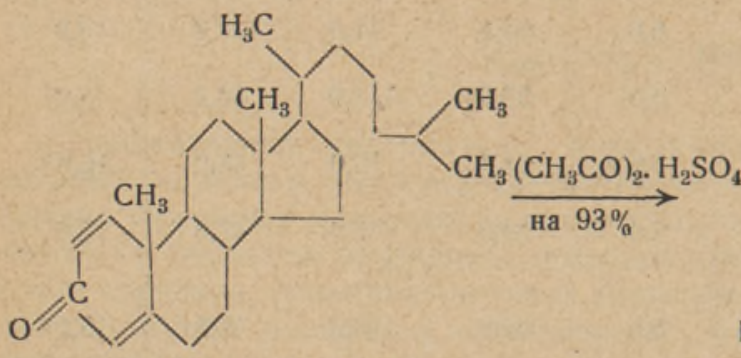

$\triangle$ 1,4-холестадиен-3-он

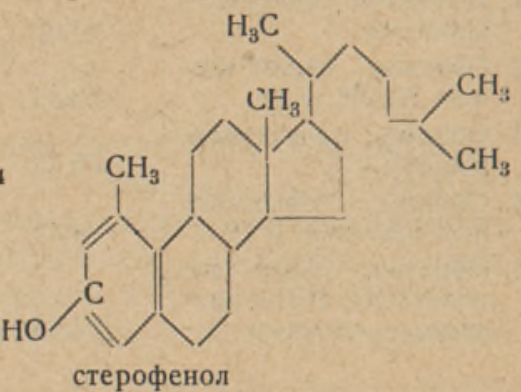

или $\triangle^{1,4}$-андростадиен-17 $\beta$-ол-3-он при нагревании в запаянной трубке при $325^{\circ}$ в течение 12 минут частично превращается в эстрадиол (с выходом $5 \%$ ). Из продуктов термической обработки выделен также метилэстрадиол. Там же указывается, что ароматизация увеличивается до 20 $60 \%$ при нагревании в среде высококипящих растворителей, могущих явиться донорами водорода. Кроме того, продукт перегруппировки (метилэстрадиол) может быть получен с выходом в $62 \%$ при воздействии уксусного ангидрида в присутствии серной кислоты.

Эти экंпериментальные данные показывают, что обработка уксусным ангидридом может привести к совершенно иным результатам, чем предполагает С. С. Семенов. Это зависит от химического строения обрабатываемого вещества, именно от порядка химической связи, а не от количества связей. В данном случае также не следует забывать, что приведенные эксперименты относятся к мономерным, хотя и относительно сложным соединениям, не связанным с другими соединениями в высокомолекулярные частицы. В случае же керогена подобного рода группировки могут составлять только какую-то часть молекулы. Не следует забывать и о том, что даже при работе с концентратами керогена, помимо органического вещества, участвует минеральная часть, которая может оказать то или иное каталитическое действие. Поэтому неправильно рассматривать ту или иную функциональную группу самостоятельно, независимо от строения частицы в целом и той среды, в которой происходит реакция. Совершенно справедливо указание В. М. Татевского о том, что свойства молекулы обусловливаются не какими-либо отдельными элементами молекулы, а всей архитектоникой молекулы, как единого целого. Приведенный экспериментальный материал, если его применить к керогену, еще лучше объясняет результаты, полученные С. С. Семеновым и его сотрудниками.

В самом деле, наличие стероидных структур в веществе кукерсита вполне реально, так как эти природные вещества имеют широкое распространение. Они имеются в морских водорослях и животных организмах, встречаются как в свободном состоянии, так и в виде простых и сложных эфиров. При прохождении через пищеварительный аппарат организмов они в большинстве случаев не разрушаются, а либо претерпевают превращения в своем ряду, либо даже гидрируются. Причем некоторые двойные связи, например при углеродных атомах $8-9$, оказываются очень 
устойчивыми как при восстановлении, так и окислении. Вместе с тем, пока не имеется никаких оснований предполагать, что при накоплении материнского вещества кукерсита были какие-то особо жесткие химические условия; об этом можно судить хотя бы по столь пышному развитию фауны в силурийском море, которое установлено геологами и палеонтологами $(5,10)$, по значительным и разнообразным минеральным остаткам организмов в отложениях кукерсита и вмещающих его пород. Следовательно, при наличии в керогене подобных стероидных структур, имеющих карбонильную группу (карбонильная группа. в керогене установлена и работами С. С. Семенова), они при термической деструкции кукерсита в определенном количестве преобразовываются в ароматические структуры, которые дают затем фенолы. При обработке же керогена спиртовой щелочью эти стероидные структуры могут претерпевать превращения, в результате которых при термической деструкции не происходит образования фенолов, и фенолы образуются только из той части структурной единицы, которая устойчива к щелочному воздействию. При обработке уксусным ангидридом ароматизация происходит в большей степени уже до термической деструкции и поэтому выход фенольной части увеличивается.

В качестве подтверждения предположения о наличии стероидных структур может служить также работа С. С. Семенова и Б. Е. Гуревич $\left({ }^{9}\right)$, установивших среди нейтральных кислородных соединений средней фракции смолы полукоксования кукерсита кетон; 4-метил-1-гидриндон, образование которого можно увязать со стероидными структурами на основании экспериментов Виндауса $\left({ }^{19}\right)$. Последний сделал наблюдение, что литобилановая кислота при нагревании разлагается с образованием пирокетона, структурно связанного с $\boldsymbol{\alpha}$-гидриндоном.

Приведенные рассуждения указывают на то, что односторонние объяснения фактов термического разложения даже предварительно обработанного керогена были бы неправильными. С другой стороны, исходя не из количества углеродных связей, а из реальной действительности, вполне вероятно предположение о наличии стероидных структур в веществе кукерсита в виде сложных и простых эфиров с кислотами и спиртами алифатического ряда, которые могли образоваться в результате разложения жировых и белковых веществ той же флоры и фауны силурийского моря. Это предположение в принципе не противоречит экспериментальным результатам окислительной, термической и восстановительной деструкции керогена кукерсита. Однако это предположение требует дальнейших многосторонних исследований, для того чтобы, основываясь на экспериментальных данных, принять или отвергнуть эту гипотезу. Весьма ценные данные, в сочетании с другими физическими и химическими методами исследования, могут дать работы по изучению функциональных групп керогена и их поведения при различных реакциях, в частности при термической деструкции. Однако было бы неправильным считать, что термическая деструкция вещества неизвестного химического строения, как кероген, может обеспечить получение всех необходимых данных для установления структуры керогена. Конечно, при одностороннем подборе фактов можно объяснить получение фенолов и ароматических углеводородов только из ароматических структур, но это не соответствует даже тем экспериментальным данным, на которые ссылается С. С. Семенов - монографию Хёрда $\left({ }^{15}\right)$. Ч. Х. Хёрд при изложении материала по пиролизу соединений углерода, наряду с указанием на образование фенолов из тех или иных производных ароматических структур, приводит и такие факты, как превращение циебеллона в тимол при $280^{\circ}$ без выделения водорода; превращение сантоновой кислоты и другие. Кроме того, даже индивидуальные соединения при термической деструкции,.в особенности в присут- 
ствии минеральных веществ, претерпевают сложный ряд превращений. Так, К. В. Топчиева и сотрудники $\left(^{12}\right)$ показали, что циклогексен на алюмосиликатном катализаторе ниже температуры крекинга подвергается реакциям полимеризации, перераспределения водорода и изомеризации. Пулегон в присутствии окиси железа при $400^{\circ}$ превращается в фенол, цимол и другие ароматические углеводороды $\left({ }^{15}\right)$ и т. д. Таким образом, сложный процесс термической деструкции может дать одни и те же конечные продукты из совершенно различных по структуре исходных веществ. И, следовательно, термическая деструкция по отношению к керогену может служить только одним из вспомогательных, но не основных методов познания, тем более, что до настоящего времени еще далеко не расшифрована индивидуальная структура продуктов термической деструкции керогена кукерсита в условиях полукоксования, а в отношении определения продуктов термической деструкции при температурах до $350^{\circ}$ делаются еще только первые шаги.

Заключая приведенный разбор статистических методов, можно сказать, что в том виде, как они предлагаются Д. В. ван Кревеленом $\left({ }^{16}\right)$, они не могут решить вопроса познания химической структуры керогена кукерсита и, очевидно, других подобных ему сложных органических соединений. Структура керогена кукерсита, несомненно, сложнее, чем структура высокоуглеродистых углистых ископаемых, в особенности близких к графиту. Если в отношении углей высокой степени углефикации, на основе физических и химических методов анализа, можно утверждать, что строение структурных единиц угля претерпевает унифицирование и что они не имеют или почти не имеют других двойных связей, кроме ароматических, то пока нет никаких оснований счнтать, что двойные связи в керогене кукерсита только ароматической природы.

Выведенные С. С. Семеновым уравнения для определения количества углеродных связей в органических соединениях и способ определения, как он называет, «излишествующих» углеродных связей в соединении, выражая только одну сторону вопроса химического строения веществ - количественную, не могут служить методом познания химической структуры не только такого сложного органического вещества, как кероген кукерсита, но и любого другого органического вещества, если невозможно установить в нем порядок химической связи непосредственно взаимодействующих элементов и влияние элементов, непосредственно не связанных валентными связями. Последний фактор, как доказано экспериментальными данными, может служить серьезным препятствием в установлении химической структуры даже относительно несложных химических соединений. Так, А. Е. Луцкий $\left({ }^{8}\right)$ показывает, что водородная связь приводит к понижению кислотных свойств фенольного гидроксила. Он указывает, что при титровании щелочью в присутствии фенолфталенна многие кислые соединения с внутримолекулярной водородной связью ведут себя вообще как нейтральные тела. Водородная связь возникает не только внутри молекулы, но образует и межмолекулярные связи,- которые также влияют на физические и химические свойства веществ. Следовательно, при изучении структуры веществ не только невозможно ограничиваться одной количественной характеристикой, но и нельзя ограничиваться порядком связеуй непосредственно связанных элементов, нельзя отрываться от строения частицы в целом и от условий химической среды.

А. М. Бутлеров $\left({ }^{3}\right)$ по такому поводу писал: «Коль скоро будет упущено из вида химическое строение как реагирующих, так и образующихся при реакции веществ, а также влияние этого строения на ход реакции, легко можно притти к мало обоснованным выводам».

Изучение химической природы керогена кукерсита, одного из наибо- 
лее древних отложений, является не простым делом, хотя бы потому, что вещество керогена содержит довольно высокий процент гетероатомов, особенно кислорода. Проведенные исследования показали, что в керогене не имеется ни гуминовых кислот, ни гуминовых веществ, в обычном понимании этих компонентов. При окислительной деструкции керогена кукерсита перманганатом калия в щелочной среде (в условиях, обеспечиваюцих необходимую сохранность продуктов деструкции) не получаются так называемые «регенерированные гуминовые кислоты» и бензолкарбоновые кислоты. Выход щавелевой кислоты может быть снижен до 3-4\%. В то же время при полукоксовании кукерсита (при выходе смолы на органическое вещество в количестве $65-66 \%$ ) получаются ароматические углеводороды и различные их гетероатомные производные, в частности фенолы, кетоны с ароматическими структурами и т. д. Своеобразие органического вещества кукерсита уже давно установлено, но причины этого своеобразия еще не раскрыты.

Потребности практики требуют выяснения химической природы керогена как для того, чтобы в соответствии с этой природой управлять промышленными процессами, так и для установления наиболее правильных путей дальнейшего использования этого природного богатства.

За последние годы этому вопросу стал уделять систематическое внимание ряд научных учреждений, в том числе институты Химии и Геологии АН ӘССР, Таллинский политехнический институт, ВНИИПС Министерства нефтяной промышленности и другие. Исследования проводятся в различных направлениях, начиная от изучения литологии отложений ордовиция (канд. геолог. наук С. С. Бауков, Институт геологии АН ЭССР), окислительной деструкции, восстановительной деструкции, термической деструкции и изучения функциональных групп керогена (С. С. Семенов, ВНИИПС, и другие). Такой разносторонний подход к изучению этого своеобразного и во всех отношениях интересного горючего ископаемого, несомненно, даст положительные результаты в разрешении стоящих перед исследователями задач. Но не следует забывать о сложности изучаемого материала. Поэтому особенно важной является уверенность в том, что химическое или иное воздействие на кероген кукерсита вызывает именно тот, а не другой ход реакции.

По поводу подхода к исследованиям весьма полезным будет привести мысли, высказанные А. М. Бутлеровым в речи «О практическом значении научных химических работ» $\left({ }^{4}\right)$. Говоря о химических анализах, как о работах, в которых химики наиболее часто встречаются с требованиями практики, А. М. Бутлеров показал, насколько огромен и сложен был труд, пока не была получена возможность пользования теми или иными методами для установления структуры анализируемого вещества. А. М. Бутлеров говорил: «Но, ясно, что, прежде чем пользоваться этими явлениями, как признаками, нужно было их изучать во всей чистоте, под известными определенными условиями, - нужно было определить все те изменения, которые эти явления могут претерпевать, когда самые условия изменяются, словом - нужно подробное и многостороннее знакомство с химическими отношениями веществ».
Институт химии
Академии наук Эстонской ССР
Поступила в редакцию $29 \times 1954$

\section{ЛИТЕРАТУРА}

1. А. М. Бутле ров, О химическом строении веществ, Избранные работы по органической химии, Изд. АН СССР, 1951.

2. А. М. Бутлеров, Современное значение теории химического строения, там же.

3. А. М. Бутлеров, О различных способах объяснения некоторых случаев изомерии, там же. 
4. А. М. Бутлеров, О практическом значении научных химических работ, там же.

5. Л. Ш. Д а в и та шв и л и, Курс палеонтологии, Госгеолиздат, Л., 1949.

6. В. В. Ко рш а к, Методы высокомолекулярной органической химин, т. I, Изд. АН CCCP, M., 1953.

7. Д. В. в а н К ре велен, Графостатистический метод изучения структуры и процессов образования угля, Химия твердого топлива, Сб. II, ИЛ, М., 1951; стр. $11-13$.

8. А. Е. Л уц ки й, Водородная связь и химические свойства органических соединений, «Успехи химин», т. XXIII, вып. 4, стр. 479, 1954.

9. С. С. С ем ено в и Б. Е. Г у ре в и ч, Изучение нейтральных кислородных соединений средних фракций сланцевой смолы, Сборник «Химия и технология продуктов переработки сланцев», Гостоптехиздат, Л., 1954, стр. 57.

10. Н. М. С т р а х ов, Основы исторической геологин, ч. І, Госгеолиздат, М.-Л., 1948.

11. В. М. Т а тев ски й, Химическое строение углеводородов и закономерности в их физико-химических свойствах, Изд. Московского университета, 1953.

12. К. В. Топ и иева, А. П. Боллод, И. В. Пацевич, И. Рти щев а, Превращения циклогексена на алюмосиликатных катализаторах с различным содержанием $\mathrm{Al}_{2} \mathrm{O}_{3}$ и $\mathrm{SiO}_{2}$ в условиях, исключающих крекинг, Известия $\mathrm{AH}$ СССР, ОХН, № 3, стр. 478, 1954 .

13. Л. Фи зе р и $М$. Фи зе р, Химия природных соединеннй фенантренового ряда, Госхимиздат, М.-Л., 1953.

14. А. С. Фоми н а и Л. Я. Побу ль, Окислительная деструкция керогена кукерсита (сообщение I), Известия АН ЭССР, т. II, № 1, 1953.

15. Ч. Х. Х ё рд, Пиролиз соединений углерода, ГОНТИ-НКТП, 1938.

16. D. W. van Krevele $\mathrm{n}$ and H. A. G. Che rmin, Chemical Structure and Properties of Coal, I - Elementary Composition and Density, „Fuel”, Vol. XXXIII, No 1, p. $79,1954$.

17. J. Schuver and D. W. va n Krevelen, Chemical Structure and Properties of Coal, III - Molar Refraction, „Fuel”, Vol. XXXIII, No 2, p. 176, 1954.

18. S. W a llis, E. Fer nholz, The Oxidation and Reduction of Dehydroandrosderone. Journal of the American Chemical Society, Vol. 57, No 8, 1511, 1935.

19. W in d a us, Annalen, 447, 233, 1926. 